\title{
An analytical biomarker for treatment of patients with recurrent B-ALL after remission induced by infusion of anti-CD19 chimeric antigen receptor $T(C A R-T)$ cells
}

\author{
Yajing Zhang ${ }^{1 \dagger}$, Wenying Zhang ${ }^{1 \dagger}$, Hanren Dai ${ }^{2 \dagger}$, Yao Wang ${ }^{2}$, Fengxia Shi ${ }^{1}$, \\ Chunmeng Wang ${ }^{1}$, Yelei Guo ${ }^{2}$, Yang Liu ${ }^{3}$, Meixia Chen ${ }^{1}$, Kaichao Feng ${ }^{1}$, Yan Zhang ${ }^{1}$, \\ Chuanjie Liu ${ }^{2}$, Qingming Yang ${ }^{1}$, Suxia Li $^{3 *} \&$ Weidong Han ${ }^{1,2,4^{*}}$ \\ ${ }^{1}$ Bio-therapeutic Department, Chinese PLA General Hospital, Beijing 100853, China; \\ ${ }^{2}$ Molecular \& Immunological Department, Institute of Basic Medicine, School of Life Sciences, Chinese PLA General Hospital, Beijing \\ 100853, China; \\ ${ }^{3}$ Department of Geriatric Hematology, Chinese PLA General Hospital, Beijing 100853, China \\ ${ }^{4}$ State key laboratory of kidney disease, Chinese PLA General Hospital, Beijing 100853, China
}

Received December 17, 2015; accepted January 19, 2016; published online March 22, 2016

\begin{abstract}
Anti-CD19 chimeric antigen receptor-modified T (CAR-T-19) cells have emerged as a powerful targeted immunotherapy for B-cell lineage acute lymphoblastic leukemia with a remarkable clinical response in recent trials. Nonetheless, few data are available on the subsequent clinical monitoring and treatment of the patients, especially those with disease recurrence after CAR-T-19 cell infusion. Here, we analyzed three patients who survived after our phase I clinical trial and who were studied by means of biomarkers reflecting persistence of CAR-T-19 cells in vivo and predictive factors directing further treatment. One patient achieved 9-week sustained complete remission and subsequently received an allogeneic hematopoietic stem cell transplant. Another patient who showed relapse after 20 weeks without detectable leukemia in the cerebrospinal fluid after CAR-T-19 cell treatment was able to achieve a morphological remission under the influence of stand-alone low-dose chemotherapeutic agents. The third patient gradually developed extensive extramedullary involvement in tissues with scarce immune-cell infiltration during a long period of hematopoietic remission after CAR-T-19 cell therapy. Long-term and discontinuous increases in serum cytokines (mainly interleukin 6 and C-reactive protein) were identified in two patients (Nos. 1 and 6) even though only a low copy number of CAR molecules could be detected in their peripheral blood. This finding was suggestive of persistent functional activity of CAR-T-19 cells. Combined analyses of laboratory biomarkers with their clinical manifestations before and after salvage treatment showed that the persistent immunosurveillance mediated by CAR-T-19 cells would inevitably potentiate the leukemia-killing effectiveness of subsequent chemotherapy in patients who showed relapse after CAR-T-19-induced remission.
\end{abstract}

chimeric antigen receptor $\mathbf{T}$ cells, B-cell acute lymphoblastic leukemia, biomarker, immunosurveillance, microenvironment

Citation: $\quad$ Zhang, Y., Zhang, W., Dai, H., Wang, Y., Shi, F., Wang, C., Guo, Y., Liu, Y, Chen, M., Feng, K., Zhang, Y., Liu, C., Yang, Q., Li, X., and Han, W. (2016). An analytical biomarker for treatment of patients with recurrent B-ALL after remission induced by infusion of anti-CD19 chimeric antigen receptor T (CAR-T) cells. Sci China Life Sci 59, 379-385. doi: 10.1007/s11427-016-5035-4

$\dagger$ Contributed equally to this work

*Corresponding author (email: lisuxia301@163.com; hanwdrsw69@yahoo.com) 


\section{INTRODUCTION}

Engineering of $\mathrm{T}$ lymphocytes to express chimeric antigen receptors (CARs) that target antigen CD19 (CAR-T-19 cells) in patients with B-cell lineage acute lymphoblastic leukemia (B-ALL) has attracted much attention because the corresponding clinical trials showed promising results: impressive clinical responses in heavily pretreated patients. Thus far, seven clinical trials involving 72 ALL patients treated with CAR-T-19 cells (targeting CD19) have been reported. These treatments induced CR in 60 (83\%) of 72 patients including patients with minimal residual disease $\left(\mathrm{MRD}^{+}\right)$or CR (Lorentzen and Straten, 2015). Particularly notable is the report of Maude where $90 \%$ of the patients were in morphological complete remission at the first assessment one month after infusion of CAR-T-19 cells (Maude, 2014). On the other hand, only statistically significant data were provided, and there are few reports about the detailed information on these patients after treatment. This year, we reported the findings from the first nine adult patients with relapsed or chemotherapy-refractory B-ALL who we enrolled in treatment with autologous or donor-derived $\mathrm{T}$ cells that were genetically modified to express a CAR targeting the B-cell antigen CD19 and harboring the 4-1BB and $\mathrm{CD} 3 \zeta$ moieties (Hanren et al., 2015). During the follow-up period, we observed interesting phenomena in three of the nine patients. Here, the details of these cases are reported.

\section{PRESENTATION OF CASES}

\section{Case 1}

Patient No. 1 from the previous report was a 49-year-old woman who had a diagnosis of Ph-positive B-ALL and never achieved molecular remission. She was BCR/ABL (breakpoint cluster region/Abelson leukemia virus) fusion gene-negative after multiple cycles of chemotherapy and treatment with molecularly targeted drugs; thus, a hematopoietic stem cell transplant was not possible. On day 23 after CAR-T-19 cell infusion, analyses of bone marrow (BM) aspiration samples from the iliac crest confirmed complete remission and BCR/ABL-negative status. Subsequently, sustained molecular remission was observed during the follow-up period of nine weeks. Consequently, the patient later underwent an HLA-matched allogeneic hematopoietic stem cell transplant from an unrelated marrow donor and has remained disease-free until now. Additionally, this patient exhibited intermittent fevers and continuous cough for the $133 \mathrm{~d}$ after the CAR-T-19 cell infusion. Laboratory testing revealed obvious upregulation of $\mathrm{C}$-reactive protein (CRP), tumor necrosis factor $\alpha$ (TNF- $\alpha)$, and interleukin 6 (IL-6). Additionally, a computed tomography (CT) scan of the lungs revealed a pulmonary infection and terminal bronchiectasis in the inferior lung that showed no noticeable improvement after multiple anti-infection treatments. These clinical signs were assumed to be the result of cytokine release syndrome (CRS). After a subcutaneous infliximab injection, the fever and cough subsided, and accordingly, the focus of infection disappeared on CT scans (Figure 1).

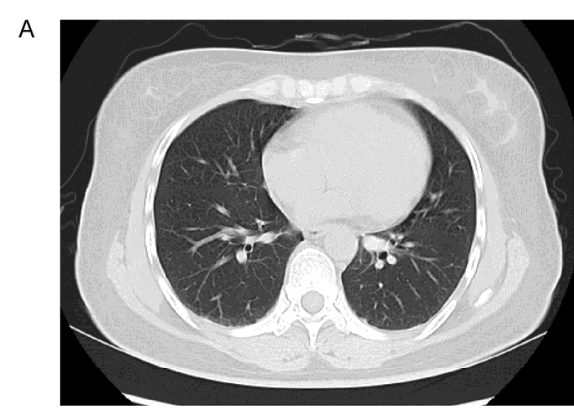

Before infusion

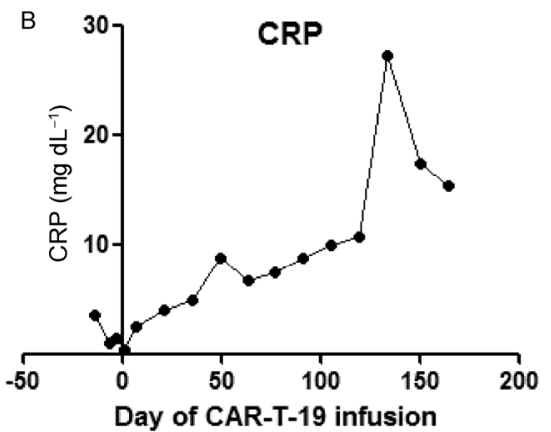

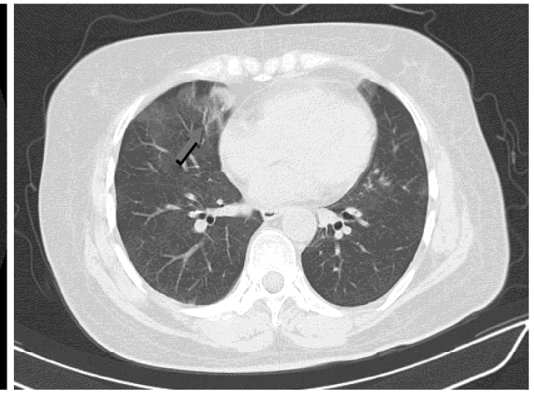

$133 \mathrm{~d}$ after CAR-T cells infusion

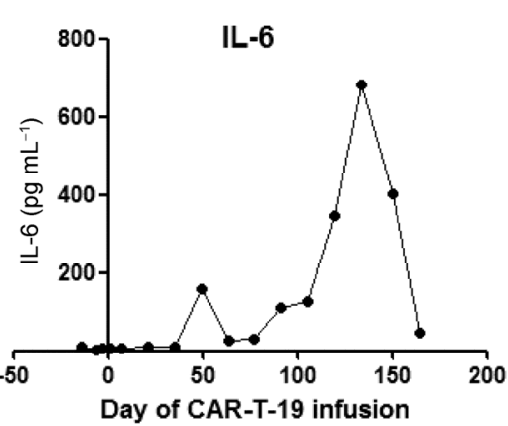

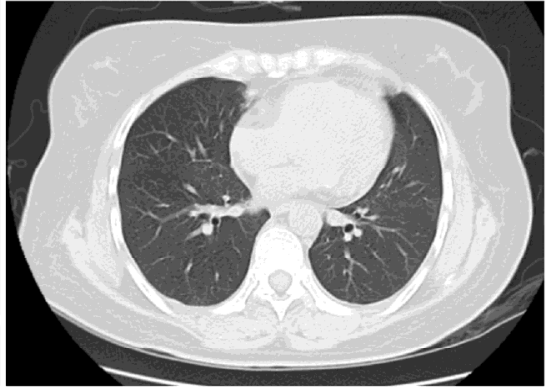

$150 \mathrm{~d}$ after CAR-T cells infusion

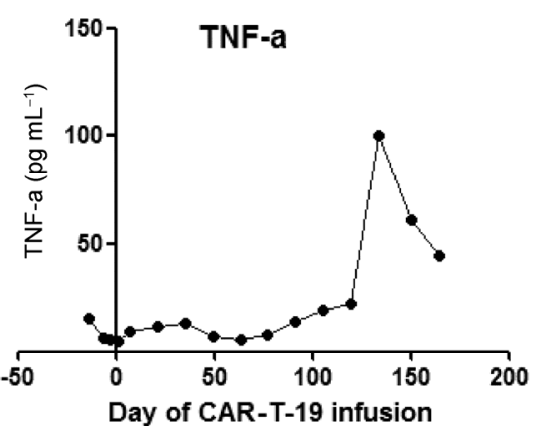

Figure 1 A, Comparison of computed tomography (CT) scans of the lungs in different periods (before, during, and after cytokine release syndrome [CRS]). Red arrows indicate infection-like responses in the lungs. B, Fluctuation of CRS-related biomarkers after infusion of anti-CD19 chimeric antigen receptor-modified $\mathrm{T}$ (CAR-T-19) cells. 


\section{Case 2}

Patient No. 6 from the previous report was a 32-year-old man with a 3-year history of chronic myelogenous leukemia who transitioned to Ph-positive B-ALL status 17 months earlier and showed detectable central nervous system (CNS) leukemia. This patient failed to achieve remission after multiple cycles of intensive chemotherapy and was referred to us for CAR-T-19 cell therapy. At the time of enrollment, he had CNS 3 status (i.e., $\geqslant 5$ white blood cells [WBCs] $\mu \mathrm{L}^{-1}$ and cytospin positivity of blasts or a traumatic spinal tap with $\geqslant 10$ red blood cells $[\mathrm{RBCs}] / \mu \mathrm{L}$ and cytospin positivity of blasts) and high cerebrospinal fluid (CSF) pressure $(\geqslant 300$ $\mathrm{mmH}_{2} \mathrm{O}$ ). Assessment on day 28 revealed minimal residual disease and complete remission with a BCR/ABL level of $0 \%$ in the CSF. The patient showed rapid relapse after the early loss of CAR-T-19 cells at 20 weeks. To our surprise, however, this patient presented with severe tumor lysis syndrome (TLS) and achieved complete remission again only after an intrathecal injection of cytarabine $(50 \mathrm{mg})$, methotrexate $(10 \mathrm{mg})$, and dexamethasone $(5 \mathrm{mg})$. Additionally, on the subsequent days, the patient showed durable remission with regular intrathecal injections each month (Figure 2).

\section{Case 3}

Patient No. 7 in the previous report was a 44-year-old man who was admitted with Ph-positive B-ALL with CNS leukemia after a relapse following an allogeneic hematopoietic stem cell transplant from an HLA-matched identical sibling donor. On treatment day 21 after the CAR-T-19 cell infusion, BM and CSF analyses confirmed complete remission and BCR/ABL negativity, respectively. The patient exhibited continued remission according to the BM and CSF tests until two or three lumps were identified in the subcutaneous tissue in the 30th week after CAR-T-19 cell infusion.

Leukemic cells were found to have generally infiltrated the adipose tissue according to a biopsy and immunohistochemical staining (IHC; Figure 3). Nearly simultaneously, the patient developed a limp, and a typical diffuse infiltrative lesion with bone destruction was directly observed on magnetic resonance imaging (MRI) of the lower limbs and lumbar vertebrae.

\section{BIOMARKERS AND SYMPTOMATOLOGY}

In the past few years, a variety of approaches based on the adoptive transfer of cells with specific and enhanced antitumor effects have been developed (Ghorashian et al., 2015; Brentjens et al., 2013; Zhu et al., 2015 ). The essential objectives of immunotherapy as a treatment of cancer are the following (Kalos, 2011): (i) to drive potent antitumor immunity that leads to remission and (ii) to establish long-lasting immunity by targeting antigens and the tumor with CAR-T cell therapies that require identification of the
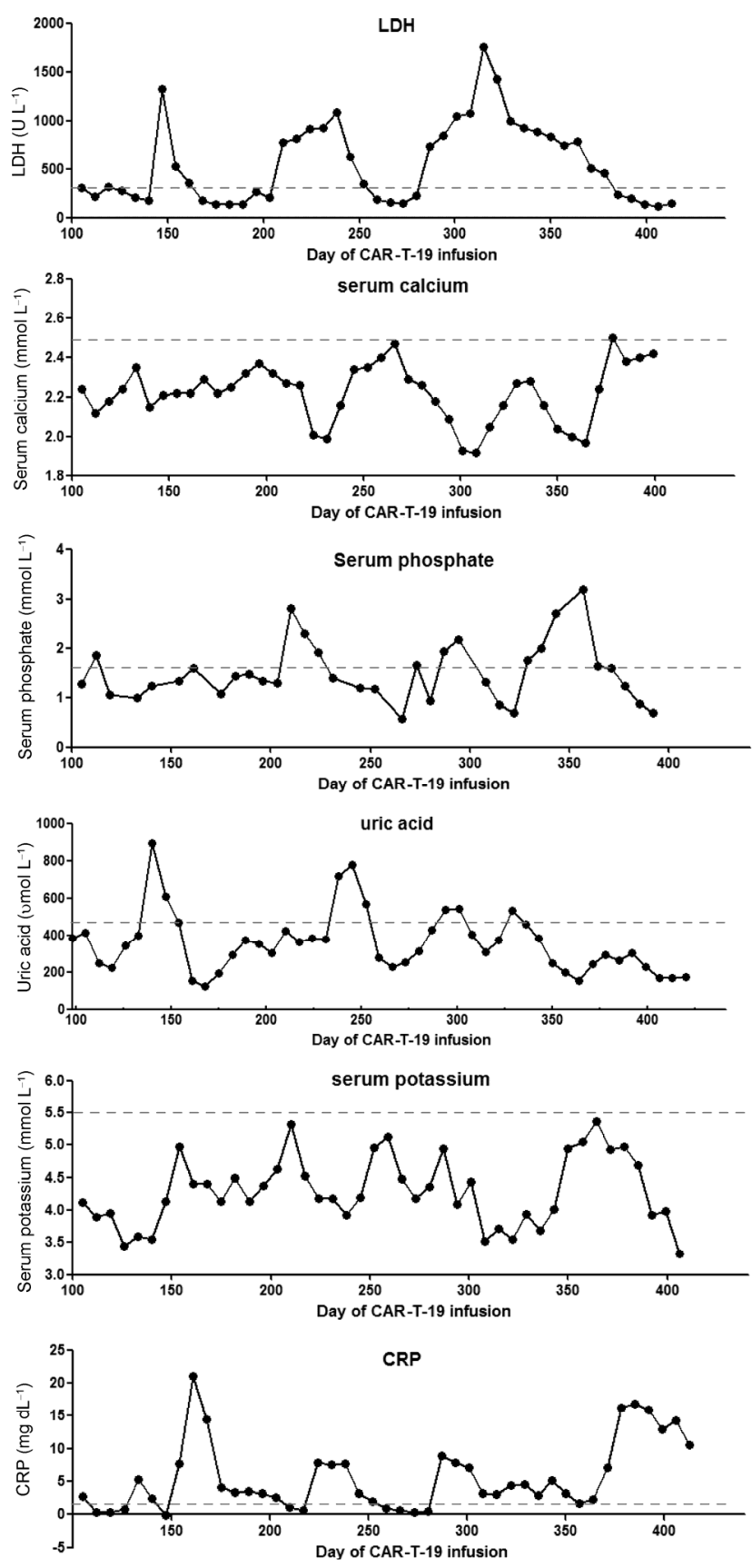

Figure 2 Fluctuation of tumor lysis-related biomarkers after single-agent low-dose chemotherapy in the patient who showed relapse after infusion of CAR-T-19 cells. Blue dotted lines represent the upper limit of the reference range of the serum indexes. The red arrows represent each injection of a chemotherapeutic agent.

relevant and informative biomarker strategies for the support, guidance, and detection of clinical developments, efficacy, clinical responses (or results), adverse effects, and the potential of such approaches to stimulate antitumor activity throughout research and development (Lacey et al., 2013). Additionally, the primary objectives of the clinical trials of CAR-T cells are to evaluate the safety and clinical efficacy of the novel therapeutic agents (Lacey et al., 2013). There- 


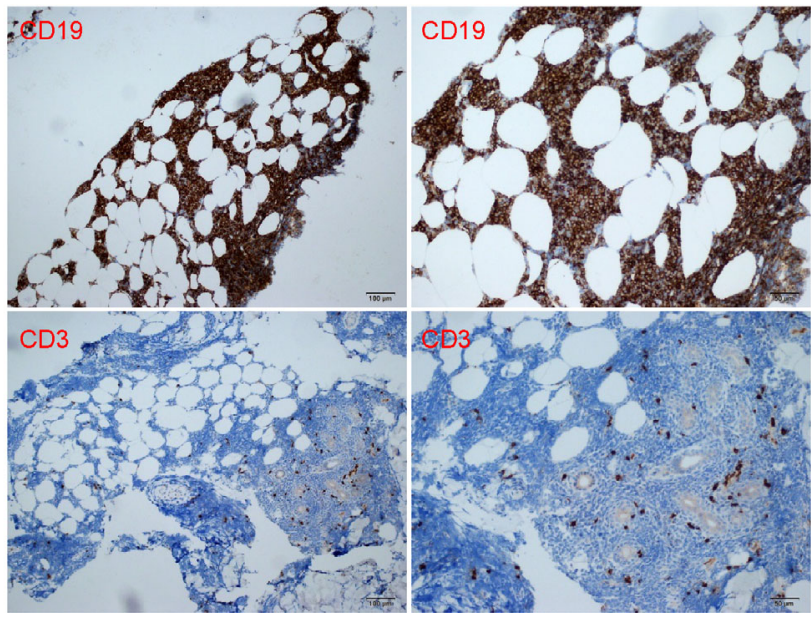

Figure 3 Biopsy samples showing extramedullary involvement in the subcutaneous adipose tissue of the chest wall and immunohistochemical staining (IHC) for CD19 and CD3; leukemic cells escape to the affected extramedullary tissue that CAR-T-19 cells could not infiltrate.

fore, we needed to define standard relevant biomarkers by first establishing principles for the development and use of biomarkers in clinical research and then by devising a rationale and a strategy for the integration of biomarker data across all stages of the product development process from preclinical studies through product manufacturing (and during the clinical trial). Finally, the different classes of biomarkers that are relevant to T-cell therapy trials have to be identified (Lacey et al., 2013). Accordingly, a CAR-T-19 cell clone was engineered for adoptive therapeutic use against cancer, and there is increasing interest in identification of sensitive, robust, and meaningful biomarkers that may provide relevant insights into the clinical development process (Fox et al., 2011; Butterfield et al., 2011).

\section{Cytokine release syndrome (CRS)-related biomarkers}

The risks associated with CAR-T cell immunotherapy can be broadly classified into autoimmune adverse effects and cytokine-associated toxicity (Lee et al.. 2014). Cytokineassociated toxicity, also known as CRS, is a nonantigen-specific toxicity that occurs as a result of high-level immune activation (Lee et al., 2014). CAR-T cells can induce a clinical syndrome involving fever, hypotension, hypoxia, and neurological changes that are associated with marked upregulation of serum cytokines in some patients (Brentjens et al., 2013; Grupp et al., 2013; Kochenderfer et al., 2012). Because CRS occurs as a direct result of supraphysiological levels of proinflammatory cytokines, circulating cytokine levels could serve as biomarkers for the diagnosis of this syndrome and for measurement of the syndrome severity (Lee et al., 2014). CRS is associated with elevated circulating levels of several cytokines, including CRP, IL-6, IL-10, and interferon $\gamma$ (IFN $\gamma$ ) (Lee et al., 2014).

\section{CRP}

This protein is an acute phase reactant produced by the liver largely in response to IL-6, and CRP levels serve as a reliable surrogate for IL-6 bioactivity (Schultz et al., 1990; Pepys et al., 2003). In some studies, peak CRP levels and fold changes in CRP have been used to identify patients who are at risk of severe CRS (Davila et al., 2014). Therefore, routine monitoring of CRP levels when CRS symptoms are present may have clinical utility (Lee et al., 2014). Nevertheless, it is important to emphasize that CRP levels are also elevated during an infection and cannot be used to distinguish infection-associated inflammation from noninfectious inflammation (Arkader et al., 2006).

\section{IL-6}

This protein is a pleiotropic cytokine with anti-inflammatory and proinflammatory properties and is involved in a large number of processes within the immune system (Lee et al., 2014; Maude et al., 2014). In patients with severe CRS associated with CAR-T cell-engaging therapies, IL-6 levels peak during maximal T-cell proliferation. Researchers theorized that targeting IL-6 might reduce CRS severity without compromising the clinical efficacy of CAR-T cell-engaging therapies (Maude et al., 2014).

\section{IL-10}

This cytokine is produced by mast cells, B cells, regulatory $\mathrm{T}$ cells, and helper $\mathrm{T}$ cells but is not commonly produced by cytotoxic $\mathrm{T}$ lymphocytes. As a negative regulator, IL-10 may not be an ideal therapeutic target in CRS (Maude et al., 2014).

\section{$I F N-\gamma$}

This IFN is also a proinflammatory cytokine and is produced by cytotoxic T cells, helper T cells (TH1), and natural killer cells (Saha et al., 2010). As an effector cytokine that is released by activated cytotoxic $\mathrm{T}$ cells after cellular engagement, IFN- $\gamma$ is expected to be upregulated and is likely required for efficacy; therefore, IFN- $\gamma$ is a potentially undesirable target for management of adverse effects (Maude et al., 2014).

\section{$T L S$}

This is a collection of metabolic aberrations that leads to a release of intracellular contents after the lysis of malignant cells and is characterized by hyperuricemia, hyperkalemia, hyperphosphatemia, and hypocalcemia that result from massive cell death and the release of intracellular uric acid, potassium, and phosphate (Will et al., 2011; Howard et al., 2011; Rasool et al., 2014). The released intracellular metabolites include nucleic acids, proteins, phosphorus, and potassium and lead to hyperuricemia, hyperkalemia, hyperphosphatemia, hypocalcaemia, and uricemia (Cairo et al., 2004). Electrolyte and metabolic disturbances can lead to 
renal insufficiency, cardiac arrhythmias, seizures, and even death due to multiple organ failure (Howard et al., 2011). The majority of TLS cases occur after treatment of a hematological cancer, such as ALL and Burkitt's lymphoma, followed by chemotherapy, radiotherapy, hormonal therapy, or immunotherapy (Rasool et al., 2014). The risk factors of TLS include a large tumor burden, high proliferation rates, and disease that is highly responsive to therapy. Studies have indicated the usefulness of blood creatinine, uric acid, lactate dehydrogenase, albumin, sodium, potassium, calcium, and phosphor in the diagnosis, prognosis, and management of TLS (Howard et al., 2011).

\section{B-cell aplasia}

Induction of B-cell aplasia is expected and indicative of functional CAR T cells in patients with relapsed acute leukemia (Grupp et al., 2013). Persistent B-cell aplasia suggests that the CAR-T-19 cells are exerting substantial and sustained effector functions in advanced ALL (Grupp et al., 2013). With the exception of B-cell aplasia, the duration of which is currently undefined, immune-system-based therapies such as CAR-T-19 may have favorable long-term profiles of adverse effects as compared to the high-dose regimens of chemotherapy and radiation therapy, which are the current standard of care for most cases of relapsed leukemia (Garcia-Manero et al., 2001).

\section{RESULTS}

\section{Persistent remission in Patient No. 1}

The clinical remission in Patient No. 1 was associated with molecular remission that persisted for more than nine weeks. Overall, this patient maintained persistent remission after the subcutaneous infliximab injections for the CRS in both lungs without any influence on the function of the CAR-T-19 cells in her body.

\section{TLS after intrathecal injection in Patient No. 6}

This patient showed relapse after the early loss of the CAR-T-19 cells at 20 weeks. Nevertheless, a rare response was observed after the intrathecal injection of cytarabine (50 mg), methotrexate (10 mg), and dexamethasone (5 mg). This patient developed severe TLS but again achieved complete remission. Additionally, in the subsequent days, he maintained durable remission with regular intrathecal injections each month. Moreover, he showed varying degrees of TLS at the time of each intrathecal injection, including the most serious complications of TLS, such as renal failure, ventricular fibrillation, and cardiac arrest. Fortunately, the patient was successfully rescued and he is currently alive and cancer free.

\section{Immune escape in Patient No. 7}

With the continuous remission in the $\mathrm{BM}$ and $\mathrm{CSF}$, this patient developed transferred extramedullary leukemia in the subcutaneous fatty tissue and skeletal system in the 30th week after CAR-T-19 cell infusion with continuous B-cell aplasia.

\section{DISCUSSION}

Relevant biomarker data can be obtained from evaluation of patients before, during, and after treatment. In particular, factors such as a patient's immune status, the tumor phenotype, and the local immune environment may influence the effectiveness of therapeutic modalities. In the present study, we sought to discuss how biomarkers can play a central role in the use of CAR-T cell therapeutic agents and to highlight how appropriately designed biomarker studies can provide critical insights into this process. Here, we discuss future directions and challenges for the appropriate use of biomarkers for evaluating product bioactivity and treatment efficacy.

\section{Adverse pulmonary events caused by the immunological responses mediated by CAR-T-19 cells}

Pulmonary events occur frequently and to varying degrees in patients who have received CAR-T cell infusions according to clinical observations. Such events are an important indicator for the development of standards for clinical trials and for identifying the differences between an infection and adverse events in the lungs. Additionally, we found that patients who develop pulmonary infiltrates exhibit more severe adverse events than do patients without pulmonary infiltrates. Wang et al. researched CD20-directed chimeric antigen receptor-modified $\mathrm{T}$ cells in a patient with primary extranodal lymphoma involving the right intrapulmonary tissue (Wang et al., 2014). This patient gradually developed dyspnea and respiratory distress, which were temporarily alleviated by intravenous administration of glucocorticoids. The patient's respiratory distress ultimately progressed until it required bed rest and the use of an oxygen mask. Consequently, extramedullary B-cell tumors in the lungs are listed as a contraindication for CAR-T therapy.

\section{Immunological tumor microenvironment (TME) and immune escape}

The term TME is used to describe certain parts of the body in which surrounding cells and tissues can affect the growth of specific cells by altering $\mathrm{pH}$, oxygen levels, and other factors (Bakker et al., 2015). The effects of the TME on hematological cancers are particularly interesting and typically involve several levels of crosstalk between leukemic cells and the bone marrow microenvironment (Bakker et al., 2015). Tumors are well adapted to overcome productive immune responses via multiple mechanisms that prevent effective killing of $\mathrm{T}$ cells and the maintenance of functional activity (Ghorashian et al., 2015). Furthermore, CAR-T-19 cells are prone to target the bone marrow rather 
than extramedullary leukemia with higher density and hypovascular regions (Yang et al., 2012; Burger et al., 2014; Christopoulos et al., 2011). Hence, the "smart leukemic cells" migrate to locations that are difficult for the CAR-T-19 cells to reach. For example, the fatty layer and the skeletal system are relatively ideal shelters for leukemic cells to escape the immunity-mediated cytocidal antitumor effect. This process may be a probable interpretation or hypothesis about the observations in patient No. 7 who showed extramedullary leukemia in the fatty layer and skeletal system without a BM and CSF relapse (Hanren et al., 2015). Eventually, future developments in CAR design need to overcome the antigenic escape and inhibition by the TME (Ghorashian et al., 2015).

\section{Immune tolerance and immunosurveillance}

The immune response is responsible for the control of nascent cancer through immunosurveillance (Schreiber et al., 2011). Eventually, the inherent genetic instability of tumor cells leads to the development of immunity evasion mechanisms, e.g., the loss of tumor-associated antigens (TAAs), downregulation of MHC antigen expression, T-cell inactivation due to reduced $\mathrm{T}$ cell receptor (TCR) signaling, and IL-10- and transforming growth factor (TGF)- $\beta$-mediated suppression (Schreiber et al., 2011). These mechanisms induce a state of immune tolerance and inactivate tumor-specific $\mathrm{T}$ cells; this situation renders the immune system incapable of recognizing TAAs and of mounting an effective immune response against them. This low immunogenicity and subsequent induction of immune tolerance remain the most difficult obstacles for effective cancer immunotherapy (Marr et al., 2012). According to the seminal theory of immune tolerance and immunosurveillance, we hypothesized that TAAs could be recognized by CAR-T-19 cells in the early period after infusion and that greater efficacy in the induction of remission could be achieved in the clinical response. Subsequently, the inherent genetic instability of leukemia leads to the loss of TAAs and development of immune evasion independent of the downregulation of MHC antigen expression. Once the TAAs are again present via intrathecal chemotherapeutic injections, they can immediately be recognized by the CAR-T-19 cells due to on-target toxicity, which stimulates a cytokine storm and subsequent organ failure. This scenario is probably the best explanation for the observation that patient No. 6 repeatedly achieved complete remission after the intrathecal injections despite the relapse of the underlying B-cell aplasia. This scenario also means that the CAR-T-19 cells still have possible powerful actions within the framework of the existing biological responsiveness.

In summary, we presented some concrete examples of CAR-T-19 cell therapy and their individual phenomena from our phase I clinical trial. Further research is needed to maximize the efficacy and to limit the adverse effects. The optimal CAR design and optimal effector T-cell populations need to be determined as does the durability of the clinical response. Moreover, personalized treatments, i.e., precise cancer therapy, should be the direction of future medical developments. The studies of individual differences in various treatment responses to achieve good resolution are expected to become the primary goal of CAR-T therapy in the future. This process will also direct and motivate us to identify imperfections and improve the process of research and development within our group.

\section{METHODS}

We analyzed three of the nine patients on whom our first report was based regarding relapsed or chemotherapy-refractory B-ALL after the administration of autologous or donor-derived $\mathrm{T}$ cells that were genetically modified to express a CAR that targets the B-cell antigen CD19 and harbored the 4-1BB and the $\mathrm{CD} 3 \zeta$ moieties. The protocol (ClinicalTrials.gov identifier NCT01864889) was approved by the Institutional Review Board of the Chinese PLA General Hospital. All authors discussed and interpreted the results and vouch for the data and analyses. No commercial sponsors were involved in the study. The materials and methods were reported previously (Hanren et al., 2015).

Compliance and ethics The author(s) declare that they have no conflict of interest.

Acknowledgements This work was supported by the National Science Foundation for Young Scientists of China (81402567, 81402566, 81472612), Bejing Nova Program (XX2016086), China Postdoctoral Science Foundation Grant (201150M1533), Science and Technology Planning Project of Beijing City (Z151100003915076 to Weidong Han), National Natural Science Foundation of China (31270820, 81230061 to Weidong Han), and People's Republic of China Support Fund (2015PC-TSYS-2013 to Suxia Li).

Arkader, R., Troster, E.J., Lopes, M.R., Júnior, R.R., Carcillo, J.A., Leone, C., and Okay, T.S. (2006). Procalcitonin does discriminate between sepsis and systemic inflammatory response syndrome. Arch Dis Child 91, 117-120.

Bakker, E., Qattan, M., Mutti, L., Demonacos, C., and Krstic-Demonacos, M. (2016). The role of microenvironment and immunity in drug response in leukemia. Biochim Biophys Acta 1863, 414-426.

Brentjens, R.J., Davila, M.L., Riviere, I., Park, J., Wang, X., Cowell, L.G., Bartido, S., Stefanski, J., Taylor, C., Olszewska, M., Borquez-Ojeda, O., Qu, J., Wasielewska, T., He, Q., Bernal, Y., Rijo, I.V., Hedvat, C., Kobos, R., Curran, K., Steinherz, P., Jurcic, J., Rosenblat, T., Maslak, P., Frattini, M., and Sadelain, M. (2013). CD19-targeted T cells rapidly induce molecular remissions in adults with chemotherapy-refractory acute lymphoblastic leukemia. Sci Transl Med 5, 177ra38.

Butterfield, L.H., Palucka, A.K., Britten, C.M., Dhodapkar, M.V., Håkansson, L., Janetzki, S., Kawakami, Y., Kleen, T.O., Lee, P.P., Maccalli, C., Maecker, H.T., Maino, V.C., Maio, M., Malyguine, A., Masucci, G., Pawelec, G., Potter, D.M., Rivoltini, L., Salazar, L.G., Schendel, D.J., Slingluff, C.L. Jr., Song, W., Stroncek, D.F., Tahara, H., Thurin, M., Trinchieri, G., van Der Burg, S.H., Whiteside, T.L., Wigginton, J.M., Marincola, F., Khleif, S., Fox, B.A., and Disis, M.L. (2011). Recommendations from the iSBTc-SITC/FDA/NCI workshop on immunotherapy biomarkers. Clin Cancer Res 17, 3064-3076. 
Burger, J.A., and Gribben, J.G. (2014). The microenvironment in chronic lymphocytic leukemia (CLL) and other B cell malignancies: insight into disease biology and new targeted therapies. Semin Cancer Biol 24, 71-81.

Cairo, M.S., and Bishop, M. (2004). Tumour lysis syndrome: new therapeutic strategies and classification. Br J Haematol 127, 3-11.

Christopoulos, P., Pfeifer, D., Bartholomé, K., Follo, M., Timmer, J., Fisch, P., and Veelken, H. (2011). Definition and characterization of the systemic T-cell dysregulation in untreated indolent B-cell lymphoma and very early CLL. Blood 117, 3836-3846.

Dai, H., Zhang, W., Li, X., Han, Q., Guo, Y., Zhang, Y., Wang, Y., Wang, C., Shi, F., Zhang, Y., Chen, M., Feng, K., Wang, Q., Zhu, H., Fu, X., Li, S., and Han, W. (2015). Tolerance and efficacy of autologous or donor-derived T cells expressing CD19 chimeric antigen receptors in adult B-ALL with extramedullary leukemia. OncoImmunology 4, e1027469.

Davila, M.L., Riviere, I., Wang, X., Bartido, S., Park, J., Curran, K., Chung, S.S., Stefanski, J., Borquez-Ojeda, O., Olszewska, M., Qu, J., Wasielewska, T., He, Q., Fink, M., Shinglot, H., Youssif, M., Satter, M., Wang, Y., Hosey, J., Quintanilla, H., Halton, E., Bernal, Y., Bouhassira, D.C., Arcila, M.E., Gonen, M., Roboz, G.J., Maslak, P., Douer, D., Frattini, M.G., Giralt, S., Sadelain, M., and Brentjens, R. (2014). Efficacy and toxicity management of $19-28 \mathrm{z}$ CAR T cell therapy in B cell acute lymphoblastic leukemia. Sci Transl Med 6, $224 \mathrm{ra} 25$.

Fox, B.A,, Schendel, D.J., Butterfield, L.H., Aamdal, S., Allison, J.P., Ascierto, P.A., Atkins, M.B., Bartunkova, J., Bergmann, L., Berinstein, N., Bonorino, C.C., Borden, E., Bramson, J.L., Britten, C.M., Cao, X., Carson, W.E., Chang, A.E., Characiejus, D., Choudhury, A.R., Coukos, G., de Gruijl, T., Dillman, R.O., Dolstra, H., Dranoff, G., Durrant, L.G., Finke, J.H., Galon, J., Gollob, J.A., Gouttefangeas, C., Grizzi, F., Guida, M., Håkansson, L., Hege, K., Herberman, R.B., Hodi, F.S., Hoos, A., Huber, C., Hwu, P., Imai, K., Jaffee, E.M., Janetzki, S., June, C.H., Kalinski, P., Kaufman, H.L., Kawakami, K., Kawakami, Y., Keilholtz, U., Khleif, S.N., Kiessling, R., Kotlan, B., Kroemer, G., Lapointe, R., Levitsky, H.I., Lotze, M.T., Maccalli, C., Maio, M., Marschner, J.P., Mastrangelo, M.J., Masucci, G., Melero, I., Melief, C., Murphy, W.J., Nelson, B., Nicolini, A., Nishimura, M.I., Odunsi, K., Ohashi, P.S., O’Donnell-Tormey, J., Old, L.J., Ottensmeier, C., Papamichail, M., Parmiani, G., Pawelec, G., Proietti, E., Qin, S., Rees, R., Ribas, A., Ridolfi, R., Ritter, G., Rivoltini, L., Romero, P.J., Salem, M.L., Scheper, R.J., Seliger, B., Sharma, P., Shiku, H., Singh-Jasuja, H., Song, W., Straten, P.T., Tahara, H., Tian, Z., van Der Burg, S.H., von Hoegen, P., Wang, E., Welters, M.J., Winter, H., Withington, T., Wolchok, J.D., Xiao, W., Zitvogel, L., Zwierzina, H., Marincola, F.M., Gajewski, T.F., Wigginton, J.M., and Disis, M.L. (2011). Defining the critical hurdles in cancer immunotherapy. J Transl Med 9, 214.

Garcia-Manero, G., and Thomas, D.A. (2001). Salvage therapy for refractory or relapsed acute lymphocytic leukemia. Hematol Oncol Clin North Am 15, 163-205.

Ghorashian, S., Pule, M., and Amrolia, P. (2015). CD19 chimeric antigen receptor $\mathrm{T}$ cell therapy for haematological malignancies. Br J Haematol 169, 463-478.

Grupp, S.A., Kalos, M., Barrett, D., Aplenc, R., Porter, D.L., Rheingold, S.R., Teachey, D.T., Chew, A., Hauck, B., Wright, J.F., Milone, M.C., Levine, B.L., and June, C.H. (2013). Chimeric antigen receptor-modified T cells for acute lymphoid leukemia. N Engl J Med 368, 1509-1518.

Kalos, M. Biomarkers in T cell therapy clinical trials. (2011). J Transl Med 9, 138.
Kochenderfer, J.N., Dudley, M.E., Feldman, S.A., Wilson, W.H., Spaner, D.E., Maric, I., Stetler-Stevenson, M., Phan, G.Q., Hughes, M.S., Sherry, R.M., Yang, J.C., Kammula, U.S., Devillier, L., Carpenter, R., Nathan, D.A., Morgan, R.A., Laurencot, C., and Rosenberg, S.A. (2012). B-cell depletion and remissions of malignancy along with cytokine-associated toxicity in a clinical trial of anti-CD19 chimeric-antigen-receptor-transduced T cells. Blood 119, 2709-2720.

Lacey, S.F., and Kalos, M. (2013). Biomarkers in T-cell therapy clinical trials. Cytotherapy 15, 632-640.

Lee, D.W., Gardner, R., Porter, D.L., Louis, C.U., Ahmed, N., Jensen, M., Grupp, S.A., and Mackall, C.L. (2014). Current concepts in the diagnosis and management of cytokine release syndrome. Blood 124, $188-195$.

Lorentzen, C.L, and Straten, P.T. (2015). CD19-chimeric antigen receptor T cells for treatment of chronic lymphocytic leukemia and acute lymphoblastic leukemia. Scand J Immunol 82, 307-319.

Marr, L.A., Gilham, D.E., Campbell, J.D., and Fraser, A.R. Immunology in the clinic review series; focus on cancer: double trouble for tumours: bi-functional and redirected $\mathrm{T}$ cells as effective cancer immunotherapies. (2012). Clin Exp Immunol 167, 216-225.

Maude, S.L., Barrett, D., Teachey, D.T., and Grupp, S.A. (2014). Managing cytokine release syndrome associated with novel $\mathrm{T}$ cell-engaging therapies. Cancer J 20, 119-122.

Maude, S.L., Frey, N., Shaw, P.A., Aplenc, R., Barrett, D.M., Bunin, N.J., Chew, A., Gonzalez, V.E., Zheng, Z., Lacey, S.F., Mahnke, Y.D., Melenhorst, J.J., Rheingold, S.R., Shen, A., Teachey, D.T., Levine, B.L., June, C.H., Porter, D.L., and Grupp, S.A. (2014). Chimeric antigen receptor T cells for sustained remissions in leukemia. N Engl J Med 371, 1507-1517.

Pepys, M.B., and Hirschfield, G.M. (2003). C-reactive protein: a critical update. J Clin Invest 111, 1805-1812.

Rasool, M., Malik, A., Qureshi, M.S., Ahmad, R., Manan, A., Asif, M., Naseer, M.I., and Pushparaj, P.N. (2014). Development of tumor lysis syndrome (TLS): a potential risk factor in cancer patients receiving anticancer therapy. Bioinformation 10, 703-707.

Saha, B., Jyothi, P.S., Chandrasekar, B., and Nandi, D. (2010). Gene modulation and immunoregulatory roles of interferon gamma. Cytokine 50, $1-14$.

Schultz, D.R., and Arnold, P.I. (1990). Properties of four acute phase proteins: C-reactive protein, serum amyloid A protein, alpha 1-acid glycoprotein, and fibrinogen. Semin Arthritis Rheum 20, 129-147.

Schreiber, R.D., Old, L.J., and Smyth, M.J. (2011). Cancer immunoediting: integrating immunity's roles in cancer suppression and promotion. Science $331,1565-1570$.

Howard, S.C., Jones, D.P., and Pui, C.-H. (2011). The tumor lysis syndrome. N Engl J Med 364, 1844-1854.

Wang, Y., Zhang, W.Y., Han, Q.W., Liu, Y., Dai, H.R., Guo, Y.L., Bo, J., Fan, H., Zhang, Y., Zhang, Y.J., Chen, M.X., Feng, K.C., Wang, Q.S., $\mathrm{Fu}, \mathrm{X} . \mathrm{B}$., and Han, W.D. (2014). Effective response and delayed toxicities of refractory advanced diffuse large B-cell lymphoma treated by CD20-directed chimeric antigen receptor-modified T cells. Clin Immunol 155, 160-175.

Will, A., and Tholouli, E. (2011). The clinical management of tumour lysis syndrome in haematological malignancies. Br J Haematol 154, 3-13.

Yang, Z.Z., and Ansell, S.M. (2012). The tumor microenvironment in follicular lymphoma. Clin Adv Hematol Oncol 10, 810-818.

Zhu, Y., Tan, Y., Ou, R., Zhong, Q., Zheng, L., Du, Y., Zhang, Q., and Huang, J. (2015). Anti-CD19 chimeric antigen receptor-modified T cells for B-cell malignancies: a systematic review of efficacy and safety in clinical trials. Eur J Haematol doi: 10.1111/ejh.12602.

Open Access This article is distributed under the terms of the Creative Commons Attribution License which permits any use, distribution, and reproduction in any medium, provided the original author(s) and source are credited. 